\title{
O aluno-problema em questão
}

Edson Soares Gomes

Centro Federal de Educação Tecnológica Celso Suckow da Fonseca

FREITAS, Marcos Cézar. Aluno-problema: forma social, ética e inclusão. São Paulo: Cortez, 2017. e-PUB.

Colocar em questão o aluno-problema é uma tarefa que exige alguns cuidados. Embora seja uma noção que pode ser facilmente situada, especialmente por remeter a situações vivenciadas no cotidiano escolar, o aluno-problema é uma noção que permite significados pouco precisos. Isto ocorre porque o termo "aluno" refere-se a pessoas que estão vinculadas a alguma instituição de ensino como estudantes. Mas a noção "problema" é capaz de se espraiar de tal forma que dificulta a construção de um consenso a respeito do seu sentido. $O$ livro do professor Marcos Cezar Freitas é ousado nesse sentido. $\bigcirc$ autor propõe, ao longo do seu livro, uma definição simples buscando indicar um sentido comum em meio a toda essa polissemia. Nele, a noção de "aluno-problema" aparece na perspectiva das dificuldades de ensino e de aprendizagem quando elas são vistas como associadas à pobreza e/ou a ambientes urbanos socialmente vulneráveis.

A infância é, portanto, o primeiro ponto abordado pelo autor para elucidar sua abordagem. Expondo, em linhas gerais, o estudo de Philippe Ariès (ARIĖS, 1978), a infância é apresentada como uma construção histórica, determinada por lugares, épocas e circunstâncias específicas sujeitas às configurações sociais e à disposição de poderes presentes em determinados momentos históricos. É a partir do enclausuramento das crianças em ambientes próprios para o tempo de escolarização, iniciado entre os séculos XVII e XVIII, que o tempo da infância configura algo paralelo ao tempo da adultez.

Freitas, também, discorre sobre a organização do tempo escolar estruturado nos rituais de simultaneidade. A experiência da seriação é, portanto, apontada como fundamental nesse processo que acaba por mesclar a contagem dos anos na infância com a progressão escolar. Em uma escola da simultaneidade e que se propõe, também, a ser escola das massas, os estudantes participam de um impiedoso jogo de comparações em que uns são 
comparados aos outros, e cada um é comparado ao conteúdo programado em cada disciplina. Professores devem ser capazes de ensinar a um maior número de estudantes um mesmo conteúdo que deve ser aprendido durante um tempo determinado.

problema ético colocado por Freitas e que se impõe à escola que assim configura, é tratar todos sob as mesmas regras mesmo não sendo capaz desconectar cada estudante da sua realidade social. Na escola da simultaneidade, os que não aprendem são considerados elementos desestabilizadores do ritmo do trabalho escolar. As desvantagens pessoais a que todos estão sujeitos, seja por uma deficiência física ou cognitiva, podem se somar às desvantagens sociais. Por esse motivo, a criança pobre se converte no eixo principal para se pensar o aluno-problema. Apesar de o tempo social da infância haver se misturado ao tempo da escolarização, as condições materiais de escolarização não se equipararam.

No terceiro capítulo, Freitas discorre, com mais profundidade, sobre os embates acerca da presença dos pobres na escola pública ao longo do processo de expansão e massificação da escola no século XX. É em um contexto que predominava a noção de "anormalidade" e da criança pobre como sendo "propensa ao crime", que se desenvolve o trabalho de Arthur Ramos (RAMOS, 1939) que fornece novas referências conceituais para pensar a presença dessas crianças na escola. Através do conceito da "criança-problema", estudantes, antes considerados "anormais", passaram a ser apontados como incompreendidos e "anormalizados" pelo meio a que pertenciam. Ramos, através da observação sistemática da vida domiciliar de crianças de escolas públicas do Rio de Janeiro, indicava, com bastante contundência, que era necessário compreender o que estava subjacente a cada "aluno-problema", pois eram, na sua maioria, crianças cujas trajetórias demonstravam que as marcas do espaço físico e suas limitações estavam combinadas com as marcas comportamentais em contraste com a moral vigente da época e ao que se esperava deles na escola. Era em função das contradições presentes no seu meio social e da escola que eles passavam a ocupar o lugar da criança-problema.

Nesta direção, se insere, também, o trabalho de Josildeth Consorte (CONSORTE, 1959). Esse contexto era influenciado pela pesquisa de Ramos, mas ainda marcado pela ideia de que o trabalho escolar era prejudicado pela intenção de integrar a escola e a favela. Consorte distingue a criança pobre de forma geral da criança favelada. Da mesma forma como a "criança 
problema", o "aluno favelado" também tinha na escola, sua formação condicionada à solução antecipada dos seus problemas familiares. Assumindo um aspecto não escolar da escola, ficavam sob a responsabilidade dos professores menos qualificadas e segregadas nas salas dos "atrasados".

Corroborando o pensamento de Arthur Ramos e Josildeth, Freitas busca, portanto, as bases para pensar o aluno-problema como estudante pobre que não aprende por trazer desvantagens sociais em face dos rituais de simultaneidade e homogeneidade na escola. Trata-se de um estudante visto como perturbador do trabalho escolar. Observando dois movimentos de inclusão, ele distingue aquele que diz respeito à ampliação do número de vagas de um segundo movimento, necessário, mas que pouco se efetivou: a inclusão ao ritmo escolar, ou seja, a impossibilidade de garantir que estudantes, mesmo em condições de desvantagem social, acompanhassem os processos de homogeneidade e simultaneidade da educação na sua forma escolar. A falta da efetividade do segundo movimento de inclusão, impôs à escola o problema ético de lidar com alguns estudantes como "indesejados".

Essa desadaptação ao ritmo escolar comum ao aluno-problema é apontada por Freitas como sendo suscetível aos preconceitos sociais produtores de diagnósticos. Nesta direção, o autor alerta para a necessidade de evitar a patologização dos problemas escolares sem negar que a medicina tem algo a informar à sala de aula. Nesta perspectiva, o estudo do aluno-problema perpassaria por questões microscópicas, por se referir não apenas a aspectos estruturais do tempo-sala de aula, mas também por questões macroscópicas, por indicar para aspectos estruturais da sociedade.

Freitas coloca, entretanto, diante de uma escola que se constituiu dependente da uniformidade dos ritmos e em que toda dissonância é apontada como atraso diante dos demais. Conforme Ramos, em 1939, trata-se de uma produção escolar que reflete aspectos das desigualdades sociais brasileiras e da organização da educação em sua forma escolar. Neste sentido, é inquestionável as contribuições que o livro traz aos estudos que pretendem discutir a situação daqueles que não são alcançados pelo sistema educacional vigente. No entanto, mais do que respostas, Freitas apresenta uma elaboração lúcida que contribui para organizar melhor as perguntas 


\section{Referências}

ARIÉS, Philippe. História social da criança e da Família. Rio de Janeiro: Editora Guanabara, 1978

CONSORTE, Josildeth Gomes. A criança favelada e a escola pública. Educação e Ciências Sociais, Rio de Janeiro, n. 4, v. 5, n. 1 1, p. 45-60, 1959. (Centro Brasileiro de Pesquisas Educacionais).

RAMOS, Arthur. A criança-problema. 2. ed. Rio de Janeiro: Caso do Estudante, 1939.

Me. Edson Soares Gomes

Centro Federal Celso Suckow da Fonseca - CEFET/RJ | Campus Itaguaí Chefe da Seção de Articulação Pedagógica Dourando em Educação Programa de Pós-Graduação da Universidade Federal do Rio de Janeiro Grupo de Pesquisa Laboratório de Pesquisa em Oportunidades Escolares

E-mail: edson.ares@hotmail.com

Recebido 22 mar. 2018 Aceito 21 maio 2018 